\title{
HARMONI SOSIAL
}

Jurnal Pendidikan IPS

- Pengaruh Pola Asuh Orang Tua, Pergaulan Teman Sebaya, Media Televisi terhadap Karakter Siswa SMP

Albertus Agung Vidi Susanto, Aman

- Efektivitas Model CTL dan Model PBL terhadap Hasil Belajar IPS Ari Wijayanti, Taat Wulandari

- Keefektifan Model TGT dan Jigsaw dengan Pendekatan Saintifik Pembelajaran Ekonomi SMA Negeri di Sleman

FX. Agus Hariyanto, Darmiyati Zuchdi

- Efektivitas Penggunaan Media Film untuk Meningkatkan Minat dan Hasil Belajar Ekonomi Siswa Kelas X Hayyun Lathifaty Yasri, Endang Mulyani

- Peningkatan Karakter Siswa Kelas IV SD Negeri 16 Ambon melalui Pembelajaran PPKn dengan Media Cerita Rakyat

Marlyen Sharly Sapulette, Amika Wardana

- Dekonstruksi Pranata Erturang pada Perkawinan Semarga (Studi Kasus Masyarakat Karo Di Berastagi)

Novrasilofa Sinulingga

Evaluasi Kinerja Guru IPS SMP Berdasarkan Standar Kompetensi Guru di

Ria Widarsih, Nahiyah Jaidi Faraz

- Pengaruh Kompetensi Guru, Motivasi Belajar, dan Lingkungan Keluarga terhadap Hasil Belajar Mata Pelajaran Ekonomi Sutardi, Sugiharsono

- Peningkatan Kualitas Pembelajaran PPKn Melalui Penerapan Problem Based Learning di SMP

Yuniwati, Muhsinatun Siasah Masruri

Himpunan Sarjana Pendidikan Ilmu-Ilmu Sosial Indonesia (HISPISI) bekerja sama dengan

Program Studi Pendidikan Ilmu Pengetahuan Sosial Program Pascasarjana Universitas Negeri Yogyakarta 


\section{잉 \\ HARMONI SOSIAL}

\section{Jurnal Pendidikan IPS}

\section{Penerbit}

Himpunan Sarjana Pendidikan Ilmu-ilmu Sosial Indonesia (HISPISI)

bekerja sama dengan

Program Studi Pendidikan Ilmu Pengetahuan Sosial

Program Pascasarjana Universitas Negeri Yogyakarta

$\begin{array}{ll}\text { Penanggungjawab } & : \text { Sardiman AM } \\ \text { Ketua } & : \text { Zamroni } \\ \text { Sekretaris } & : \text { Muhsinatun Siasah Masruri } \\ \text { Penyunting } & : \text { Aman } \\ & \text { Samsuri } \\ & \text { Sukirno } \\ & \text { Amika Wardana } \\ & \text { Taat Wulandari } \\ \text { Penyunting Bahasa } & : \text { Suhardi } \\ & \text { Rahmat Nurcahyo }\end{array}$

\section{Koordinator Jurnal PPs UNY}

Ashadi

\section{Sekretariat}

Rohmat Purwoko

Syarief Fajaruddin

SEMUA TULISAN YANG ADA DALAM HARMONI SOSIAL JURNAL PENDIDIKAN IPS

BUKAN MERUPAKAN CERMINAN SIKAP DAN ATAU PENDAPAT DEWAN REDAKSI

TANGGUNGJAWAB TERHADAP ISI DAN ATAU AKIBAT DARI TULISAN TETAP TERLETAK PADA PENULIS

Alamat Sekretariat Redaktur dan Tata Usaha:

Program Studi Pendidikan IPS, Program Pascasarjana Universitas Negeri Yogyakarta

Jln. Colombo Karangmalang Yogyakarta 55281

Homepage: http://journal.uny.ac.id/index.php/hsjpi

Email journal.pps@uny.ac.id jurnalppsuny@yahoo.com

Harmoni Sosial Jurnal Pendidikan IPS terbit 2 kali setahun pada bulan Maret dan September 


\section{KATA PENGANTAR}

Puji syukur kita panjatkan ke hadirat Tuhan Yang Maha Esa atas limpahan rahmat-Nya sehingga Himpunan Sarjana Ilmu-Ilmu Sosial Indonesia (HISPISI) bekerja sama dengan Program Studi Pendidikan Ilmu Pengetahuan Sosial Program Pascasarjana Universitas Negeri Yogyakarta dapat menerbitkan Harmoni Sosial Jurnal Pendidikan IPS Volume 3, Nomor 2, September 2016.

Harmoni Sosial Jurnal Pendidikan IPS memuat naskah-naskah dan menyebarluaskan hasilhasil penelitian dan pemikiran dosen, penelitian tesis mahasiswa S2, dan penelitian disertasi mahasiswa S3 dari berbagai perguruan tinggi di Indonesia. Hasil-hasil penelitian dan pemikiran yang disampaikan pada jurnal ini memuat naskah-naskah IPS secara terpadu, sejarah, ekonomi, sosiologi, dan geografi, serta ilmu-ilmu sosial lain yang relevan. Harapannya jurnal ini bermanfaat bagi pengembangan ilmu-ilmu sosial secara komprehensif dan juga pendidikan ilmu-ilmu sosial secara lebih khusus.

Redaksi sudah berusaha semaksimal mungkin dalam menampilkan naskah-naskah yang berkualitas namun Dewan redaksi tetap mengharap masukan dan kritik membangun dari civitas akademika agar terbitan beikutnya akan makin baik dan berkualitas. Adanya kekurangankekurangan pada jurnal ini kiranya dapat dimaklumi. Atas perhatian pembaca dan bantuan mitra bestari, editor, dan karywan Program Pascasarjana Universitas Negeri Yogyakarta hingga dapat diterbitkannya jurnal ini diucapkan terima kasih.

Yogyakarta, September, 2016

Ketua Redaksi 


\section{HARMONI SOSIAL \\ JURNAL PENDIDIKAN IPS}

Volume 3, Nomor, 2, September 2016

\section{DAFTAR ISI}

1. Pengaruh Pola Asuh Orang Tua, Pergaulan Teman Sebaya, Media Televisi terhadap Karakter Siswa SMP.

Albertus Agung Vidi Susanto, Aman

2. Efektivitas Model CTL dan Model PBL terhadap Hasil Belajar IPS Ari Wijayanti, Taat Wulandari

3. Keefektifan Model TGT dan Jigsaw dengan Pendekatan Saintifik Pembelajaran Ekonomi SMA Negeri di Sleman

FX. Agus Hariyanto, Darmiyati Zuchdi

4. Efektivitas Penggunaan Media Film untuk Meningkatkan Minat dan Hasil Belajar Ekonomi Siswa Kelas X

Hayyun Lathifaty Yasri, Endang Mulyani

5. Peningkatan Karakter Siswa Kelas IV SD Negeri 16 Ambon melalui Pembelajaran PPKn dengan Media Cerita Rakyat

Marlyen Sharly Sapulette, Amika Wardana

6. Dekonstruksi Pranata Erturang pada Perkawinan Semarga

(Studi Kasus Masyarakat Karo Di Berastagi)....

$166-176$

Novrasilofa Sinulingga

7. Evaluasi Kinerja Guru IPS SMP Berdasarkan Standar Kompetensi Guru di Kabupaten Kebumen

Ria Widarsih, Nahiyah Jaidi Faraz

8. Pengaruh Kompetensi Guru, Motivasi Belajar, dan Lingkungan Keluarga terhadap Hasil Belajar Mata Pelajaran Ekonomi.

Sutardi, Sugiharsono

9. Peningkatan Kualitas Pembelajaran PPKn Melalui Penerapan Problem Based Learning di SMP

$199-210$

Yuniwati, Muhsinatun Siasah Masruri 